\title{
A Survey on the Integration of Spiritual Care in Medical Schools from the German-Speaking
} Faculties

\section{Mara Taverna' \\ Pascal O Berberat ${ }^{2}$ \\ Heribert Sattel' \\ Eckhard Frick (D) ${ }^{\prime}$}

'Department of Psychosomatic Medicine \& Psychotherapy, TUM School of Medicine, Technical University of Munich, Munich, Germany; ${ }^{2}$ Medical Education Center, TUM School of Medicine, Technical University of Munich, Munich, Germany

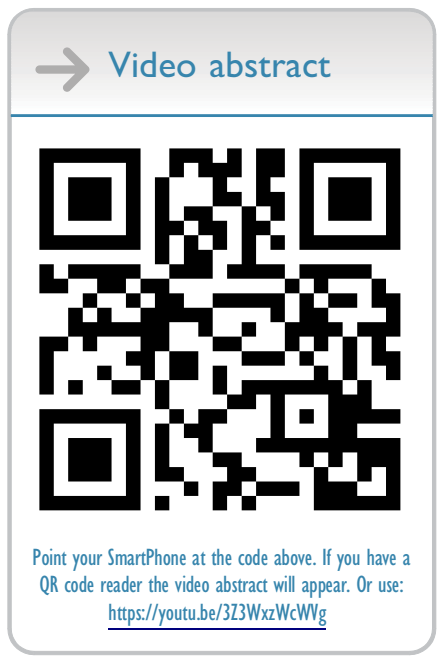

Correspondence: Eckhard Frick

Department of Psychosomatic Medicine \& Psychotherapy, Klinikum rechts der Isar, Technical University of Munich, Munich, Germany

Email eckhard.frick@tum.de
This article was published in the following Dove Press journal:

Advances in Medical Education and Practice

Objective: Teaching about spirituality and health is recommended by the American Association of Medical Colleges and partially implemented in some US medical schools as well as in some faculties of other countries. We systematically surveyed Medical School Associate Deans for Student Affairs (ADSAs) in three German-speaking countries, assessing both projects on and attitudes towards Spiritual Care (SC) and the extent to which it is addressed in undergraduate (UME), graduate (GME), and continuing (CME) medical education (in this article, UME is understood as the complete basic medical education equivalent to college and Medical School. GME refers to the time of residency).

Methods: We executed a cross-sectional qualitative complete online-survey, addressing ADSAs of all accredited 46 medical schools in these countries. Anonymized responses could be analyzed from 25 (54.3\%).

Results: No faculty provides a mandatory course exclusively dedicated to SC. Fourteen medical schools have UME courses or contents on SC, and 9 incorporate SC in mandatory classes addressing other topics. While most of the respondents indicate that spirituality is important for (a) the patients for coping and (b) for health care in general and thus, support the teaching of SC in UME, only half of them indicate a need for an SC curriculum in UME. Even if funding and training support were available, only a few of the respondents would agree to provide more of the sparse curricular time.

Conclusion: A majority of the participating medical schools have curricular content on SC, predominantly in UME. However, most of the content is based on voluntary courses. Despite acknowledging its importance to patients, ADSAs and medical teachers are still reflecting on the divergences in patients' and doctors' spiritual orientations and its consequences for implementing spirituality into the medical education.

Keywords: medical education, spiritual care, hidden curriculum, existential, religious

\section{Introduction}

The WHO defines Spiritual Care (SC) as a pillar of Palliative Care, respecting the variety of religious, existential, and spiritual orientations and belongings among patients and caregivers. Beyond palliative care, SC is being more and more embraced and taught in other medical areas such as psychiatry, ${ }^{1}$ internal medicine, ${ }^{2}$ and general practice. ${ }^{3,4}$ In addition, Palliative and Spiritual Care training formats are being extended to all health professionals. ${ }^{5} \mathrm{SC}$ encompasses a shared responsibility of physicians and other health professionals for patients' - and also their own - spiritual, existential, and religious needs, resources or distress. The 
terminology (spiritual, existential, or religious) is still controversial. $^{6,7}$ In the present study, we describe those terminological differences and we discuss the underlying world-views.

Twenty years ago, the US Medical School Objectives Project (MSOP) defined the following Learning Objectives Relevant to Spirituality and Cultural Issues:

1. The ability to elicit a spiritual history;

2. The ability to apply the understanding of a patient's spirituality and cultural beliefs and behaviors to appropriate clinical contexts (eg, in prevention, case formulation, treatment planning, challenging clinical situations);

3. An understanding of, and respect for, the role of clergy and other spiritual leaders, and culturally based healers and care providers, and how to communicate and/or collaborate with them on behalf of patients' physical and/or spiritual needs;

4. An understanding of Health Professionals' own spirituality and how it can be nurtured:

- as part of their professional growth, promotion of their well-being, and

- as the basis of their calling as a physician, ${ }^{8}$ importantly contributing to students' emotional well-being. ${ }^{9-11}$

We share these learning objectives and describe the current situation of SC training in German-speaking medical schools. They then make suggestions as to which advancements in the field should be implemented in the Germanspeaking region. They subscribe to initiatives such as the US-wide inter-professional SC education curriculum development promoted and coordinated by the George Washington Institute for Spirituality and Health, ${ }^{12}$ serving as a model for implementing SC training in different cultural, political, and linguistical contexts. In the meantime, there have been several didactic and conceptual studies conducted in various countries: the US, ${ }^{13}$ Near East, ${ }^{14}$ in Iran, ${ }^{15,16}$ in Brazil, ${ }^{17}$ in the United Kingdom, ${ }^{18,19}$ and in Canada. ${ }^{20}$ In some countries, such as Germany, SC training is a compulsory part of the UME palliative care teaching. Previous research ${ }^{17,18}$ shows, however, that in some regions UME SC modules are still optional and oriented towards particularly motivated students. Furthermore, there seems to be a discrepancy between the students' perceived need for spiritual education and the teachers' doubts on the needed extent of such teaching and by whom it should best be taught. ${ }^{17,18}$ Several studies analyzed the facilitators and barriers to doctors providing SC. Surprisingly, neither lack of time nor economic reasons, but rather insufficient training in $\mathrm{SC}$ are stated as the major barriers in addressing religious or spiritual issues with patients. ${ }^{21-25}$ Additionally (and without doubt more pronounced in Europe than in the US), for many physicians, it is counter-cultural to openly discuss spirituality, and they even cite fear, shame, and discomfort as a barrier to proactively eliciting spiritual concerns. ${ }^{19}$ Already in UME, discomfort concerning SC may stem from individual factors and from a (mis)match in religion between doctor and patient. ${ }^{26}$

The present study aims to report SC teaching in German-speaking medical schools and to examine the ADSAs' (or substitutes chosen by them to respond for them) attitudes and curriculum development in this field. Our study addresses the following research questions:

1. How do the respondents evaluate the importance of SC training for developing new patient-centered methods in UME, GME, and CME?

2. How frequently do medical schools integrate SC training into all three levels of medical education?

3. Are new methods, objectives, approaches, and structures planned for teaching $\mathrm{SC}$, and if so, which ones?

4. In what aspects do medical schools which foster SC training differ from those schools that are more hesitant about (or even resist) such training?

\section{Methods}

In order to achieve these measures, we carried out a crosssectional qualitative study, which was intended as a complete survey.

Data collection: From all 46 accredited medical schools in the three German-speaking countries, the ADSAs were initially contacted in order to identify the person in each faculty who might best judge the SC Program. We first sent out an invitation letter, and one week later, we sent an email link for the corresponding online questionnaire to the ADSAs or to the person identified by the ADSAs as suitable respondents. In the case of non-respondence within three weeks, follow-up by telephone, postal mail, and email sought to maximize the response rate. The questionnaire was generated and delivered as TAN-encrypted online-survey using "EvaSys" (https://www.evasys.de/evasys-education.html). The data were completely anonymized. 
Twenty-seven out of 45 medical schools responded. One of the ADSAs explicitly refused to take part in the study and was removed from the sample. Another questionnaire was sent back empty and therefore was removed from the sample, resulting in 25 included medical schools (response rate 54.3\%). The presented results refer to a varying number of responses (Figure 1), as some of the respondents - mainly those for GME and CME - discontinued when reaching a chapter which was not applicable to their particular medical school.

\section{Questionnaire}

According to the majority of medical publications about spirituality and health, the questionnaire introduced "spirituality" as an umbrella term including religion, existential reflection, and other personal convictions which may be called "spiritual" by the patient. In accordance with the non-exclusive connotations of the terms in question, the respondents should be free to differentiate between these terms according to their preferred wording. Consequently, ADSAs or identified respondents were asked about their general understanding of SC and its perceived importance in patient treatment and $\mathrm{ME}$.

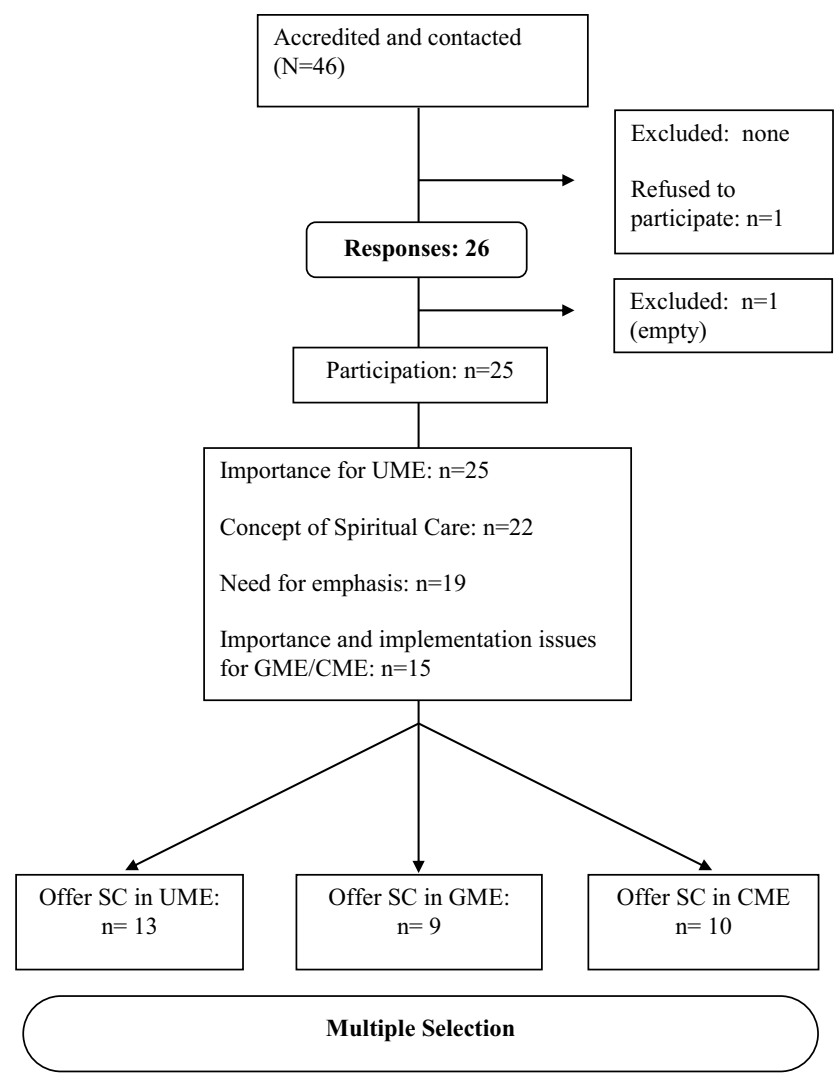

Figure I Included medical schools (study flowchart).
Furthermore, we investigated in detail at which levels teaching of SC takes place during medical education (UME, GME, and CME) and - where applicable - how the teaching programs are structured.

The questionnaire contains 52 questions in total, eliciting 8 yes/no statements, 21 multiple-choice answers, and 7 rating items (Likert scaled, ranging from 1 (example: "not at all important") to 6 (example: "fully important")), and 16 free-text answers. The questionnaire was divided into 4 sections, with section 3 pertaining to the three different levels of ME:

1) General information on the location of the university (2 multiple-choice questions)

2) Definition \& importance: general understanding of $\mathrm{SC}$ in terms of perceived importance in patient care $(2$ multiple-choice questions, 1 rating item)

3) Curriculum: $\mathrm{SC}$

a) in UME (14 multiple-choice questions, 3 rating items)

b) in GME (3 multiple-choice questions, 1 rating item)

c) in CME (3 multiple-choice questions, 1 rating item)

d) as post-graduate course (3 multiple-choice questions)

4) Didactics: open/optional suggestions for new SC teaching methods in $\mathrm{ME}$

\section{Data Presentation}

Multiple choice and rating scales were analyzed in a descriptive manner, resulting in frequencies of the given responses. The free-text answers underwent a qualitative contents analysis $\left(\mathrm{QCA}^{27}\right)$ in order to identify relevant general topics and to determine the frequency of those topics.

\section{Results}

Considering all three German-speaking countries under question, the participation rates were as follows: in Germany, out of 39 medical schools, 19 responded (48.7\%). In Austria, all four medical schools (100.0\%) participated, and in Switzerland, two of the three German-speaking medical schools responded (66.7\%). In Germany, the response rate differed depending on the federal state (data not shown).

As an introduction and in order to estimate the relevance of the topic for ME, we asked: "How important are spiritual/religious/existential subjects in health care?" A large majority rated SC in patient treatment as very or fully important (global rating). Respondents could differentiate between spiritual, religious, and existential topics. Figure 2 shows the different ratings for domains which are considered important for patient care. 


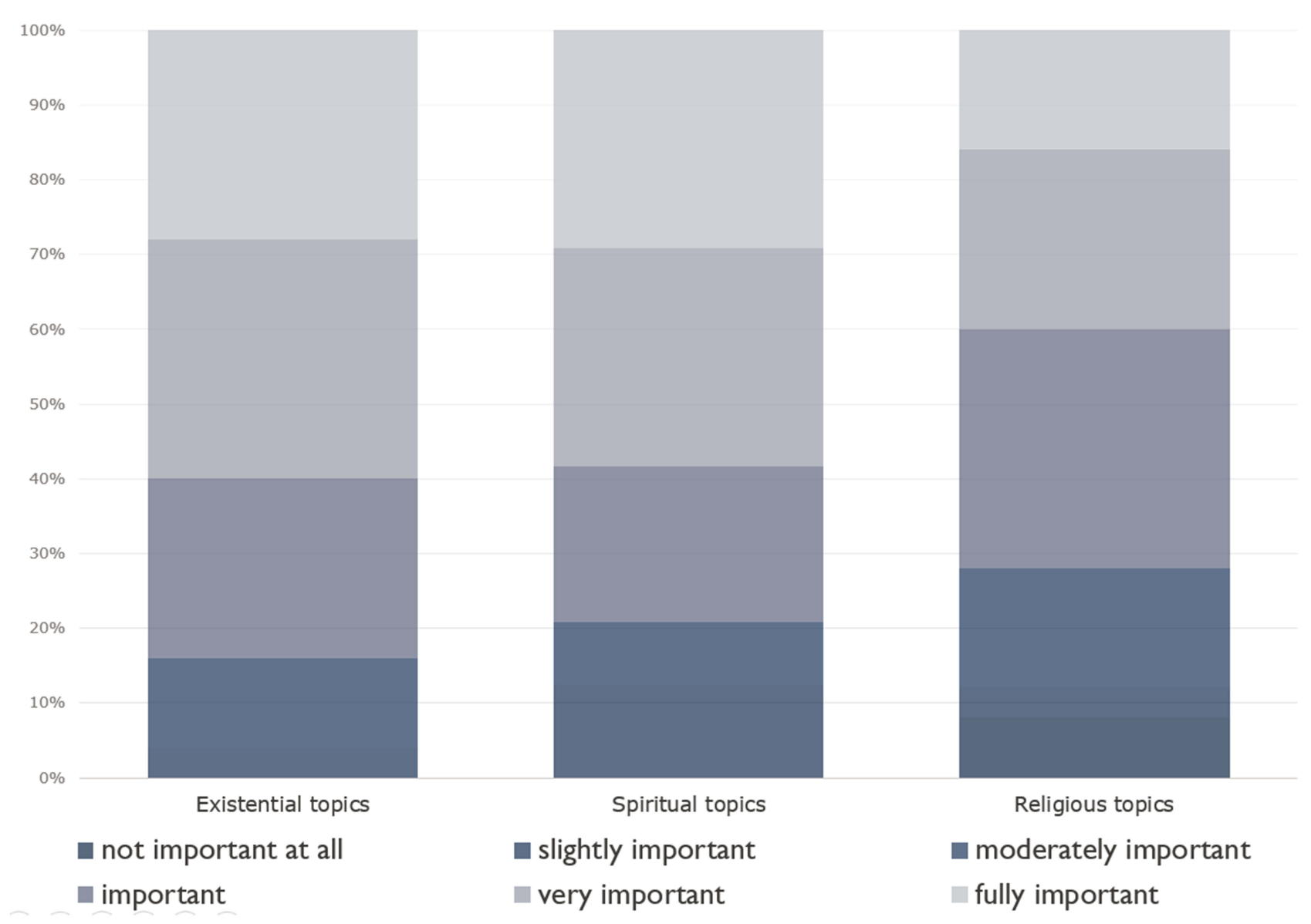

Figure 2 Perceived importance of spiritual care aspects in patients' treatment.

\section{Understanding SC as a Medical Subject}

Thirteen medical schools offer UME and could, therefore, provide further detailed information. Most of the respondents consider SC to be an integration of existential and spiritual themes in the curriculum, whereas the integration of religious topics seems less important for the majority. None of the respondents regard existential and spiritual topics as "not important at all" (results not shown).

The present study assumes SC to be a general, inter-faith (trans-religious) responsibility of health professionals and takes into account the somewhat indistinct boundaries between the main categories, which refer to it. The respondents were asked to formulate their personal approach to SC, responding to the question: "How do you personally understand the field of 'SC'?" Half of the elicited 22 responses defined SC as taking into account the spiritual/religious/ existential needs of the patients and relatives in the treatment plan ( $\mathrm{n}=11)$. Less frequent were responses such as "to raise consciousness in the professional team about spiritual aspects of patient care" $(\mathrm{n}=5)$, or a multi-professional approach of the patient care, team-like support from disciplines like palliative care, psychology, psycho-oncology, self-aid, chaplain/spiritual/religious care $(n=5)$.

One respondent stated that he or she had never heard of $\mathrm{SC}$ before being invited to this review.

\section{SC in the Different Levels of Medical Education}

In German-speaking countries, medical schools are primarily responsible for UME and not for GME and CME. However, academic teachers from the medical schools share certain responsibilities in postgraduate programs with academic teaching hospitals outside the universities and medical associations. Consequently, medical schools provide SC teaching at different levels of medical education and in different combinations. Interestingly, 13 of the responding medical schools indicate SC teaching in UME. Those 12 medical schools which offer SC teaching in more than $1 \mathrm{ME}$ level also 


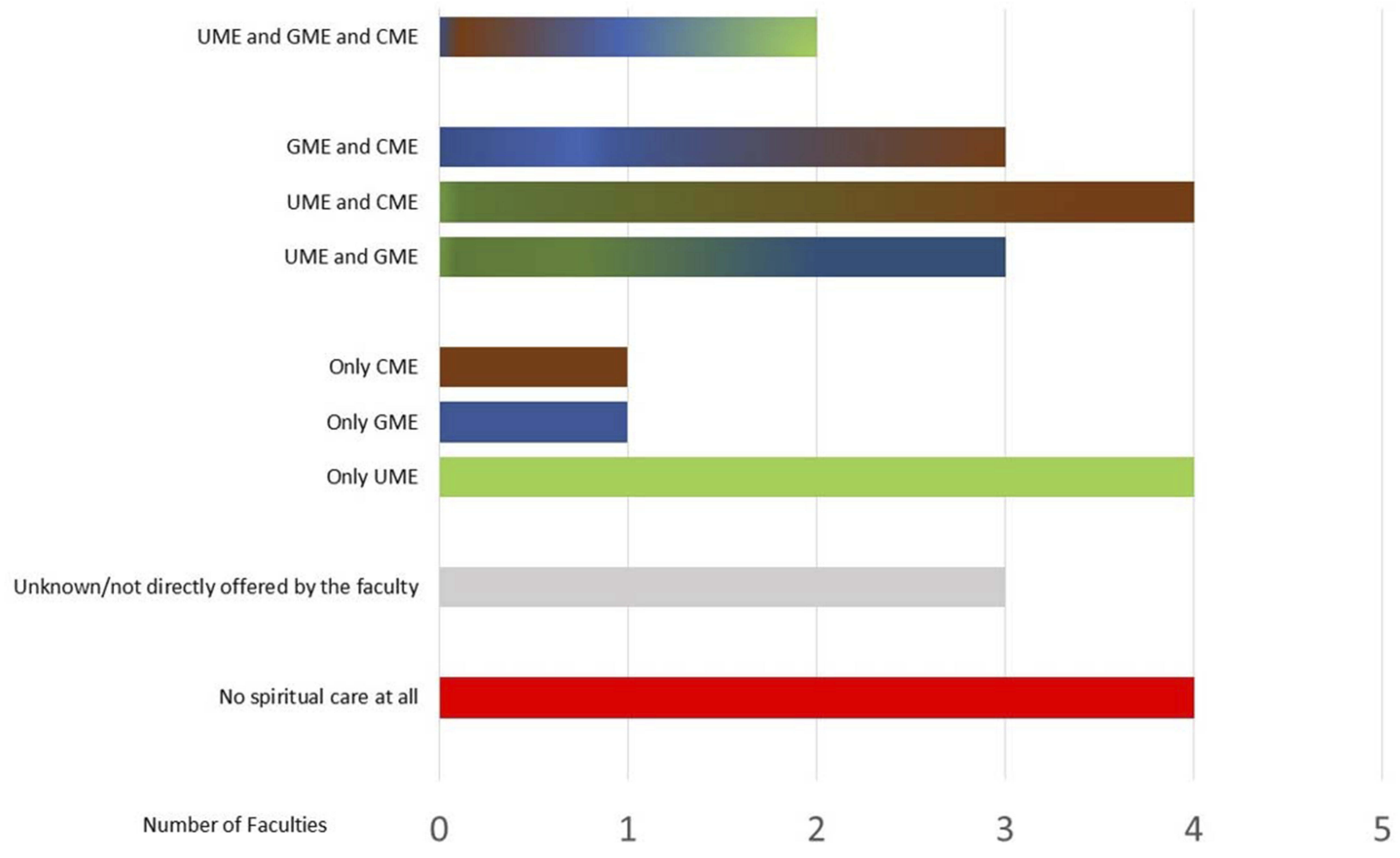

Figure 3 Implementation of spiritual care teaching on different levels of the education program (multiple choice).

assign higher scores concerning the general importance of the subject (see Figure 3): all of them reported 100\% very/fully important scores (5 and 6). Particularly, the two medical schools which offer SC teaching in all three educational steps (UME, GME, and CME) are the ones with the highest score ( $6=$ fully important) in the Likert Scale measuring the perceived value of SC (results not shown). One respondent mentions that the SC teaching in their faculty is provided by chaplains and not by the medical professionals. Another respondent mentions that palliative care is in charge of their SC education.

Furthermore, we asked the respondents whether they consider a (new) specific course for SC necessary or not. Almost the whole range of answers was given. A slight majority $(\mathrm{n}=13)$ indicate that they do not see much need for a specific course on SC (scores 1 and 2). However, a significant number $(\mathrm{n}=10)$ considers a specific course on $\mathrm{SC}$ at least moderately important (scores 4,5 , and 6 ).

\section{Undergraduate Medical Education}

The questions concerning UME yielded 13 responses. SC teaching mainly takes place in the context of palliative medicine $(n=12)$ and/or psychosomatic classes $(n=4)$ as part of compulsory courses. Psychiatry and general medicine, as well as pediatric and internal medicine, are also mentioned as fields where SC is part of the program. Five institutions offering SC teaching in more than one subject also score high in the value they attribute to the importance of SC in patients' treatment (Figure 2, scores 5 and 6). There are different ways in which SC is taught. However, the classical lecture format is predominant. Still, some use eLearning formats and seminars as well. These virtual formats are interprofessionally open, especially for students in nursing and social work. None of the universities has a teaching entity exclusively entitled "SC". Some respondents remark that $\mathrm{SC}$ is taught in certain courses without being specifically labeled as such. In most cases, SC teaching takes place between the 3rd and the 5th year of medical studies. On average, a teaching program lasts up to $4 \mathrm{hrs}$ during the whole course. Nevertheless, it has also been mentioned that it is difficult to assess the exact number of hours taught because SC is often incorporated into other courses, as mentioned earlier. Medical doctors $(n=10)$, psychologists $(n=9)$ and chaplains $(n=10)$ are the professional figures involved in teaching SC. Table 1 shows the topics currently taught in the SC context (multiple choice). 
Table I Topics Currently Taught in the Spiritual Care Context (Undergraduate Medical Education, Multiple Choice)

\begin{tabular}{|l|l|}
\hline Teaching Content & $\mathbf{n}$ \\
\hline Doctor-patient communication & 12 \\
Perception of spiritual aspects of the patient & 12 \\
Handling seriously ill patients and their relatives & $1 \mathrm{I}$ \\
Difference between religiousness and spirituality & 10 \\
Definition of spirituality & 9 \\
Handling spiritual/religious aspects of the patient & 9 \\
Breaking bad news & 9 \\
Grief/mourning/bereavement & 9 \\
Spiritual self-assessment & 5 \\
Spiritual anamnesis & 5 \\
Role of spirituality in the health care system & 4 \\
Others & 2 \\
\hline
\end{tabular}

Table 2 Topics the Respondents Would Like to Strengthen in Undergraduate Medical Education (Multiple Choice)

\begin{tabular}{|l|l|}
\hline Teaching Content Needs & $\mathbf{n}$ \\
\hline Role of spirituality in the health care system & 9 \\
Finding and self-evaluation of own spirituality & 9 \\
Perception of spiritual aspects of the patient & 9 \\
Spiritual self-assessment & 9 \\
Grief/mourning/bereavement & 8 \\
Handling spiritual/religious aspects of the patient & 7 \\
Doctor-patient communication & 6 \\
Spiritual anamnesis & 5 \\
Definition of spirituality & 5 \\
Difference between religiousness and spirituality & 5 \\
Breaking bad news & 4 \\
Others & 1 \\
\hline
\end{tabular}

In Table 1, the most prominent topic in SC teaching is the common and nonspecific label "doctor-patient communication". More specific topics such as "definition of spirituality" and "handling spiritual/religious aspects of the patient" are less frequently reported. In order to gain insight into how to improve UME SC teaching in the future, we asked the faculty members what they felt was missing or not yet adequately addressed in the teaching content. These data include responses from 6 respondents who do not yet offer SC courses in UME.

A comparison between Tables 1 and 2 shows that some of the already addressed issues entail a further need in training and clinical practice and require practical improvement.

Table 2 shows that topics such as "role of spirituality in the health care system" and "finding and self-evaluation of own spirituality" need to be addressed more in the curricula.
Table 3 Patients' Perspective and Doctors'/Students' Perspective Categories

\begin{tabular}{|l|l|}
\hline Category & Quotes \\
\hline Patients' perspective & $\begin{array}{l}\text { For patients whose spiritual needs arise } \\
\text { during their illness spiritual care can give } \\
\text { comfort in case of seriously ill and dying } \\
\text { outcomes }\end{array}$ \\
\cline { 2 - 3 } & $\begin{array}{l}\text { The spiritual side of a disease is usually the } \\
\text { part which receives less attention, while } \\
\text { exactly this side is perceived as the most } \\
\text { relevant by the patient. }\end{array}$ \\
\cline { 2 - 3 } & $\begin{array}{l}\text { Through spiritual care, patients can also get } \\
\text { to learn self-care. }\end{array}$ \\
\cline { 2 - 3 } & $\begin{array}{l}\text { Spiritual care should be integrated as a basic } \\
\text { element in the medical approach to the } \\
\text { disease. }\end{array}$ \\
\hline Health professionals' & $\begin{array}{l}\text { Spiritual care can contribute to seeing the } \\
\text { human being as a whole, and a regular } \\
\text { teaching of this subject should help students } \\
\text { be better prepared for the clinical practice. }\end{array}$ \\
\cline { 2 - 3 } & $\begin{array}{l}\text { The international shift of the society } \\
\text { demands more and more skills in this } \\
\text { direction. }\end{array}$ \\
\cline { 2 - 3 } & $\begin{array}{l}\text { Physicians suffer from high burn-out rates and } \\
\text { lack of self-care in the clinical setting. } \\
\text { Promoting spiritual care in the sense of self- } \\
\text { care and resilience could positively affect } \\
\text { doctors and therefore patient's well-being. }\end{array}$ \\
\hline
\end{tabular}

Similarly, topics like "perception of spiritual aspects of the patient", "handling spiritual/religious aspects of the patient", and "sadness", though they are already part of the curricula, at least to a certain degree, need to be extended on in the SC program. A comparison between Tables 1 and 2 shows that some of the already addressed issues entail a further need in training and clinical practice and require practical improvement. This is particularly true for issues pertaining to the perception and handling of spirituality in patients. In $n=7$ medical schools, the teaching content of SC courses does end with a proficiency test on the subject, while $n=4$ of the courses do not test the students at all (no data provided by 2 participants).

Considering the full sample, 16 respondents report that it is not yet clear whether or not fundamental objections to/reservations about including SC teaching in the undergraduate medical studies exist. A few respondents who indicate reservations about it $(n=3)$ mention in free-text answers that the concept of SC 
can be misunderstood as an intrusion of the church, thus, giving the subject "Spiritual Care" a negative association with religion. In these few cases, religiousness is not considered an appropriate topic within a neutral context like medicine. Six out of 25 respondents say that there are no objections to/reservations about SC teaching in their undergraduate medical studies, and in free-text answers, they report that this topic is incorporated in many different courses. Moreover, one respondent says that the involvement of the faculty management in SC enhances the sensibility and the integration of such themes in the curriculum. One respondent reports that the teaching hours dedicated to the topic are too few to be able to address the topic in a satisfying manner.

\section{Should SC Have More Value in UME?}

Nineteen respondents provided data on the need for a stronger focus on $\mathrm{SC}$ in UME. $\mathrm{N}=10$ respondents report the need to dedicate more time to SC teaching in UME. Nine of them give detailed explanations on why there is a need for giving more space to $\mathrm{SC}$ in the undergraduate medical education. The answers were analyzed and arranged in two main categories, ie, patients' perspective and doctors'/students' perspective:

Two respondents report that in their opinion there is no need for providing more space to SC teaching in UME. The explanations as given in their free-text answers are as follows: topics of SC teaching are already integrated into different subjects without needing a specific course and a specific labeling as "SC"; it should be present only as an extra-offer for people who are interested in the topic. $\mathrm{N}=7$ respondents are undecided about whether there is an actual need for allocating more time to SC teaching in their medical schools.

\section{Graduate (GME) and Continuing (CME) Medical Education}

The questions concerning GME and CME yielded 15 and 14 responses, respectively.

\section{How Important Is SC in GME?}

All but one respondent indicate that $\mathrm{SC}$ in this educational step is "moderately important", "very important", or "fully important". The most frequent rating is "fully important".

Six respondents are in favor of allocating more time to $\mathrm{SC}$ in the graduate education, while 8 are still undecided whether this subject needs more dedication or not. One respondent would not spend more time on SC in GME. The respondents who give lower scores for the perceived value of SC (Figure 2) are also those who are undecided whether this subject really matters in the graduate education or not.

\section{How Important Is SC in CME?}

The answers to this aspect were highly heterogeneous. Except for one respondent, all others indicate that SC in this educational step is, at least, of some importance. Like in UME and GME, medical doctors, psychologists, and chaplains are the professionals mostly involved in the teaching of SC. However, the nursing staff plays a minor, yet important role on all three levels of medical education as well. The answers show that in continuing medical education mainly medical doctors participate in specific courses on SC.

In $\mathrm{CME}, 5$ respondents would dedicate more time to $\mathrm{SC}$, while 7 are still undecided whether this subject needs more space or not. Further, 2 respondents do not consider it necessary to provide more space to SC teaching during continuing medical education. Respondents who give lower scores for the perceived value of SC are, again, also the ones who are undecided whether this subject really matters in the continuing medical education or not. In one case, the participant explicitly mentions that training in SC at his/her university is adequately provided for, with no need to give more meaning/ space to the topic. The question of why they see the need to provide further teaching in SC in continuing medical education was commented on by 5 respondents in free-text form as follows: in summary, the course selection on topics pertaining to SC is poor. Particularly medical doctors in this ME step face difficulties in recognizing spiritual needs and addressing $\mathrm{SC}$ with patients. Moreover, they mention the importance that medical staff should be comfortable with handling such needs of patients, even of atheists/agnostics.

\section{Discussion}

The present study is unique because it provides, for the first time, data on SC teaching in German-speaking medical schools. Regarding the research questions formulated in the Introduction of this study, the results allow to state the following:

1. A majority of the respondents consider SC important for patient care and consequently foster the implementation of SC training into the medical education. 
2. Some medical schools in German-speaking countries integrate SC training into all levels of medical education, especially in UME.

3. New methods of teaching SC in German-speaking countries are the use of online courses as well as extending SC teaching beyond "end of life care".

4. Medical schools which foster SC training are more likely to provide not only UME teaching but also SC courses in GME and CME, facilitating life-long learning in this field.

The present study yielded a response rate of $54.3 \%$, comparable to previous surveys in other regions. ${ }^{13,17,19,28}$ The $\mathrm{SC}$ concept has historical roots in the interprofessional palliative care movement. It may successfully be broadened and adapted to other clinical fields ${ }^{29}$ such as surgery/anesthesiology. ${ }^{30}$ This implies that SC should be included as a meaningful topic in the syllabus of UME and should be taught by teachers who have been specifically trained in SC. Concerning UME, our respondents reported no required courses exclusively dedicated to SC (US 7\% ${ }^{13}$ UK $5.6 \%{ }^{19}$ ) but added that $\mathrm{SC}$ is incorporated within standard curriculum. A British study ${ }^{18}$ found students more open toward SC than teachers. A Dutch group ${ }^{31}$ found a discrepancy between the perceived importance of palliative care among last year medical students and their feeling of low confidence in providing such care, especially in dealing with the spiritual aspect of it. A Spanish study $^{32}$ yielded similar results.

What is the necessary "dose" of SC during UME? Based on our data, we estimate that the medical schools of our survey provide an average of $4 \mathrm{hrs}$ during the whole course. A recent US-American study ${ }^{33}$ reports that 150 mins during the whole UME course $(60$ mins lecture focusing on religion/spirituality in health care, followed by a 90-min case discussion in a small group setting) may improve the students' attitudes and competencies in this field.

As far as the overall importance of SC teaching is concerned, we have seen that the wording (spiritual, existential, religious, humanitarian, etc.) and the teaching contents have to be distinguished. One respondent, for example, wrote to us:

Having worked for many years in palliative care and in cooperation with chaplains, I do not see the utility of the 'spiritual care' concept. Nevertheless, I understand the meaning of your question, and according to this I will answer your questions.

In the present survey, the respondents ascribe less importance of SC to CME than to UME and GME. At the same time, there are in German-speaking countries, various projects of specialized curricula in conventional classroom style and in virtual conferences, addressing all health professionals. Outcome data about CME courses, eg, in palliative care, ${ }^{14,34}$ are sparse.

Several authors report training programs in psychiatry and psychotherapy in order to fill the "religiosity gap"35 between patients and their therapists. ${ }^{36}$ US-American initiatives such as the Spiritual CompetencyTraining in Mental Health (SCT-MH), a 7-hr asynchronous, online program consisting of 8 modules $^{37}$ may be a model for the German-speaking region. Kelley et $\mathrm{al}^{38}$ report a community-based training for improving knowledge of African-American spiritualities. Finding the right words and concepts in spiritual dialogs with psychiatric patients requires a hermeneutic approach, translating the patients' and the health professional's worldview and finding a common ground. ${ }^{39}$

This leads up to the question of which obstacles stand in the way of further SC-implementation in Medical Education. A major barrier, and perhaps the most important one for medical teachers, has been called medicine's "hidden curriculum": the unconscious, implicit, or informal curriculum behind the formal one. The hidden curriculum is highly ambivalent: on the one hand, it may be the inspiring role model of an experienced and empathic clinical teacher. On the other hand, however, the hidden curriculum may, "foster being singularly focused on advancement within medicine or on self-promotion that can create conflict within work relationships" ${ }^{\prime 0}$ and hinder the student from being sensitive to the patient's suffering. According to Balboni et al, primary religious/spiritual resources prior to medical socialization may be a buffer against the hidden curriculum's destructive sides. Sajja and Puchalski ${ }^{41}$ suggest "training physicians as healers" in order to overcome the discrepancy between medicine's scientific and spiritual sides. For people with different cultural backgrounds, SC may foster a spirit of empathy $^{42}$ and "hospitality" in medical schools in spite of scientifically or personally motivated "hostilities". 43 Especially in the European situation, SC is not opposed to evidence-based medicine's skeptical and critical roots. On the contrary, the dialogic concept of spirituality 
encompasses this "scientific spirit" in physicians as well as in patients. All in all, in order to reach a "fully fledged" integration of SC, interdisciplinary research and SC courses should be mandatory in the medical curriculum. ${ }^{44}$ Undoubtedly, the concept of "transcendence" (ie, what is beyond the boundaries of our observed, controlled, and medically curable world) is still uncommon in medical research, however respected by a large part of health professionals. ${ }^{8}$ Consequently, our results as well as previous studies, ${ }^{13,19}$ show that SC is already integrated into $\mathrm{ME}$.

Another important aspect has to be regarded, namely, the different cultural facets of ME. Western ME, viewed from other traditions such as Islamic medicine, has for a long time neglected the humanitarian, cultural, religious, and spiritual dimensions of healing. ${ }^{16,45}$ These dimen-

Box I Improving SC Teaching in Medical Schools (Repondents' Suggestions Summarized)

- Definitions of specific learning goals in the forthcoming UME masterplan

- Embedding SC in the clinical routine

- Sensitization about this subject in the UME, GME, and CME using "train the trainers" meetings

- Identifying SC subjects in ME fields not explicitly dedicated to SC

- Integration of SC into Disease-Management Programs

- Fostering the matching between patients 'spiritual needs and health professionals' spiritual competence

- Learning from SC in the palliative context and transferring this knowledge to other clinical and ME fields

- "It should be seen as an integral part of caregiving/practice and not some sort of odd special add-on"

sions, however, are increasingly being addressed by medical teachers, especially in the USA and the American continent, and to a non-English speaking) Europe is strongly marked by the skepticism of enlightenment and by scientific positivism. In addition, some of our respondents share the opinion that the term "spirituality" is too broad and may possibly just be a synonym for medicine's humanistic side. ${ }^{6}$ However,

The definition of spirituality used in clinical care and in medical education is intentionally broad to be inclusive of the diverse ways people understand transcendent meaning in their lives. ${ }^{7}$

The role of religion and spirituality is an important cultural asset in medical students, impacting the way they find meaning in their lives as medical students, and how they anticipate using it in their work as physicians. ${ }^{37,46}$ Similar studies about medical students' religious and spiritual orientations are still missing in the German-speaking region.

Despite existing individual and cultural reluctances toward SC teaching, the ADSAs or other respondents answering to the present survey made numerous suggestions on how to improve SC-teaching in medical schools, which are summarized in Box 1.

\section{Limitations}

Given the response rate of 54\%, a "pro-spiritual" bias (more responses of those who are positive towards and willing to take some time for SC) must be considered. Due to anonymization sensitivity analyses or even a simple check for representativity - in particular, for Germany - is not feasible. The non-exclusive nature of the terms (existential/spiritual/religious) under question does not allow strict distinctions for statements, which include all these components of SC, unless stated otherwise.

\section{Conclusion}

This survey describes how SC training is currently implemented in German-speaking medical faculties. SC training is generally provided, at least in UME and, to a lesser extent, in GME and CME. A large proportion of the respondents underline the meaningfulness of SC and see at least some need for modifications of existing content and/or additional courses.

What can we learn when comparing SC programs in other countries or world regions with the scarce curriculum in German-speaking medical schools? Providing SC in health care and teaching it to students depends on institutional, cultural, and personal factors. Considering the facilitators and barriers to SC can potentially enhance and transform medical practice into being more interdisciplinary, patient-centered, and resource-oriented, bridging the gap between "to cure" and "to care".

\section{Abbreviations}

ADSA, Medical School Associate Dean for Student Affairs; CME, Continuing Medical Education; GME, Graduate Medical Education; SC, Spiritual Care; UME, Undergraduate Medical Education. 


\section{Ethical Approval}

This study has been approved by the Technical University of Munich (School of Medicine) ethics committee (109/18 S).

\section{Disclosure}

The authors report no conflicts of interest in this work.

\section{References}

1. Moreira-Almeida A, Sharma A, Rensburg B, Verhagen PJ, Cook CCH WPA position statement on spirituality and religion in psychiatry; 2015. Available from: http://www.wpanet.org/uploads/Position_Statement/ WPA $\% 20$ position $\% 20$ Spirituality $\% 20$ statement $\% 20$ final\%20version rev2\%20on\%20Spirituality.pdf. Accessed May 8, 2016.2.

2. Piscitello GM, Martin S. Spirituality, religion, and medicine education for internal medicine residents. Am J Hospice Palliative Care. 2019;1049909119872752.

3. Bornet M-A, Edelmann N, Rochat E, Cornuz J, Poncin E, Monod S. Spiritual care is stagnating in general practice: the need to move towards an embedded model. Br J Gen Pract. 2019;69(678):40. doi:10.3399/bjgp19X700613

4. Strassner C, Frick E, Stotz-Ingenlath G, et al. Holistic care program for elderly patients to integrate spiritual needs, social activity, and self-care into disease management in primary care (HoPES3): study protocol for a cluster-randomized trial. Trials. 2019;20(1):364. doi:10.1186/s13063-019-3435-z

5. Winterkorn-Dezorzi L, Raymundo MM, Goldim JR, de Oliveira CAV. Spirituality in the continuing education of healthcare professionals: an approach to palliative care. Palliat Support Care. 2019;1-6. doi:10.1017/S1478951519000117

6. Salander P, Hamberg K. Why "spirituality" instead of "the humanistic side of medicine"? Acad Med. 2014;89(11):1430. doi:10.1097/ ACM.0000000000000492

7. Puchalski CM, Blatt B, Handzo G. In reply to Salander and Hamberg. Acad Med. 2014;89(11):1430-1431. doi:10.1097/ACM.0000000000 000498

8. AAMC. Transcendence, religion and spirituality in medicine: medical students' point of view. Report III of the Medical School Objectives Project. Contemporary issues in medicine: communication in medicine. United States 1999. Available from: https://members.aamc.org/eweb/ upload/Contemporary\%20Issues\%20In\%20Med\%20Commun $\% 20$ in $\%$ 20Medicine\%20Report\%20III\%20.pdf. Published October 1999. Accessed February 27, 2019.

9. Ayala EE, Omorodion AM, Nmecha D, Winseman JS, Mason HRC. What do medical students do for self-care? A student-centered approach to well-being. Teach Learn Med. 2017;29(3):237-246. doi:10.1080/10401334.2016.1271334

10. Estupiñan B, Kibble J. The relationship between spirituality and burnout in the lives of medical students. Med Sci Educ. 2018;28 (1):37-44. doi:10.1007/s40670-017-0490-5

11. Dyrbye LN, Sciolla AF, Dekhtyar M, et al. Medical school strategies to address student well-being: a national survey. Acad Med. 2019. doi:10.1097/ACM.0000000000002611

12. GWish. George Washington Institute for Spirituality and Health, School of Medicine and Health Sciences. Interprofessional spiritual care education curriculum (ISPEC). Available from: https://smhs. gwu.edu/gwish/interprofessional-spiritual-care-education-curriculumispec. Accessed March 10, 2019. 2018.

13. Koenig HG, Hooten EG, Lindsay-Calkins E, Meador KG. Spirituality in medical school curricula: findings from a national survey. Int J Psychiatry Med. 2010;40(4):391-398. doi:10.2190/ PM.40.4.c
14. Bar-Sela G, Schultz MJ, Elshamy K, et al. Training for awareness of one's own spirituality: a key factor in overcoming barriers to the provision of spiritual care to advanced cancer patients by doctors and nurses. Palliat Support Care. 2019;17(3):345-352.

15. Memaryan N, Rassouli M, Nahardani SZ, Amiri P. Integration of spirituality in medical education in Iran: a qualitative exploration of requirements. Evid Based Complement Alternat Med. 2015;2015:793085. doi:10.1155/2015/793085

16. Hausteiner-Wiehle C, Henningsen P. Kein Befund und trotzdem krank? Mehr Behandlungszufriedenheit im Umgang mit unklaren Körperbeschwerden - bei Patient und Arzt. Mit einem Geleitwort von Antonius Schneider. Stuttgart: Schattauer; 2015.

17. Lucchetti G, Lucchetti ALG, Espinha DCM, de Oliveira LR, Leite JR, Koenig HG. Spirituality and health in the curricula of medical schools in Brazil. BMC Med Educ. 2012;12:78. doi:10.1186/1472-6920-12-78

18. Harbinson MT, Bell D. How should teaching on whole person medicine, including spiritual issues, be delivered in the undergraduate medical curriculum in the United Kingdom? BMC Med Educ. 2015;15:96. doi:10.1186/s12909-015-0378-2

19. Culatto A, Summerton CB. Spirituality and health education: a national survey of academic leaders UK. J Relig Health. 2015;54 (6):2269-2275. doi:10.1007/s10943-014-9974-4

20. Daudt H, d'Archangelo M, Duquette D. Spiritual care training in healthcare: does it really have an impact? Palliat Support Care. 2018;17:1-9.

21. Balboni MJ, Sullivan A, Amobi A, et al. Why is spiritual care infrequent at the end of life? Spiritual care perceptions among patients, nurses, and physicians and the role of training. J Clin Oncol. 2013;31(4):461-467. doi:10.1200/JCO.2012.44.6443

22. Best M, Butow P, Olver I. Do patients want doctors to talk about spirituality? A systematic literature review. Patient Educ Couns. 2015;98(11):1320-1328. doi:10.1016/j.pec.2015.04.017

23. Paal P, Helo Y, Frick E. Spiritual care training provided to healthcare professionals: a systematic review. J Past Care Counsel. 2015;69 (1):19-30. doi:10.1177/1542305015572955

24. Koenig HG, Perno K, Hamilton T. Effects of a 12-month educational intervention on outpatient clinicians' attitudes and behaviors concerning spiritual practices with patients. Adv Med Educ Pract. 2017;8:129-139. doi:10.2147/AMEP.S125352

25. Kichenadasse G, Sweet L, Harrington A, Ullah S. The current practice, preparedness and educational preparation of oncology professionals to provide spiritual care. Asia Pac J Clin Oncol. 2017;13(5): e506-e514. doi:10.1111/ajco.12654

26. Schmidt C, Nauta L, Patterson M, Ellis A. Medical students' (dis) comfort with assessing religious and spiritual needs in a standardized patient encounter. J Relig Health. 2019;58(1):246-258. doi:10.1007/ s10943-018-0714-z

27. Mayring P. Qualitative content analysis. In: Flick U, Kardoff E, Steinke I, editors. A Companion to Qualitative Research. London: Sage; 2000:266-269.

28. Lambie D, Egan R, Walker S, MacLeod R. How spirituality is understood and taught in New Zealand medical schools. Palliat Support Care. 2015;13(1):53-58. doi:10.1017/S147895151300062X

29. Crawford GB, Zambrano SC. Junior doctors' views of how their undergraduate clinical electives in palliative care influenced their current practice of medicine. Acad Med. 2015;90(3):338-344. doi:10.1097/ACM.0000000000000632

30. Atkinson HG, Fleenor D, Lerner SM, Poliandro E, Truglio J. Teaching third-year medical students to address patients' spiritual needs in the surgery/anesthesiology clerkship. Mededportal. 2018;14:10784. doi:10.15766/mep_2374-8265.10784

31. Pieters J, Dolmans DHJM, Verstegen DML, Warmenhoven FC, Courtens AM, van den Beuken-van Everdingen MHJ. Palliative care education in the undergraduate medical curricula: students' views on the importance of, their confidence in, and knowledge of palliative care. BMC Palliat Care. 2019;18(1):72. doi:10.1186/ s12904-019-0458-x 
32. de Diego Cordero R, Lucchetti G, Fernández-Vazquez A, BadantaRomero B. Opinions, knowledge and attitudes concerning "spirituality, religiosity and health" among health graduates in a Spanish university. J Relig Health. 2019;58(5):1592-1604. doi:10.1007/ s10943-019-00780-3

33. Smothers ZPW, Tu JY, Grochowski C, Koenig HG. Efficacy of an educational intervention on students' attitudes regarding spirituality in healthcare: a cohort study in the USA. BMJ OPEN. 2019;9(4): e026358-e026358. doi:10.1136/bmjopen-2018-026358

34. Wasner M, Longaker C, Fegg MJ, Borasio GD. Effects of spiritual care training for palliative care professionals. Palliat Med. 2005;19 (2):99-104. doi:10.1191/0269216305pm995oa

35. Dein S, Cook CCH, Powell A, Eagger S. Religion, spirituality and mental health. Psychiatrist. 2010;34(2):63-64. doi:10.1192/pb. bp. 109.025924

36. Gattari T, Arfken C, Morreale M. Perspectives of religion and spirituality in psychiatry: a comparison of students, residents, and attending physicians. Acad Psychiatry. 2018;42(1):176-178. doi:10.1007/ s40596-017-0845-7

37. Pearce MJ, Pargament KI, Oxhandler HK, Vieten C, Wong S. A novel training program for mental health providers in religious and spiritual competencies. Spirituality Clin Pract. 2019;6(2):73-82. doi:10.1037/scp0000195

38. Kelley FR, Haas GL, Felber E, Travis MJ, Davis EM. Religious community partnerships: a novel approach to teaching psychiatry residents about religious and cultural factors in the mental health care of African-Americans. Acad Psychiatry. 2019;43(3):300-305. doi:10.1007/s40596-018-1010-7
39. Frick E. Charting Spiritual Care - psychiatric and psychotherapeutical aspects. In: Peng-Keller S, Neuhold D, editors. Charting Spiritual Care - The Emerging Role of Chaplaincy Records in Global Healthcare. Springer Nature; 2019:21-32.

40. Balboni MJ, Bandini J, Mitchell C, et al. Religion, spirituality, and the hidden curriculum: medical student and faculty reflections. J Pain Symptom Manage. 2015;50(4):507-515. doi:10.1016/j.jpainsymman. 2015.04.020

41. Sajja A, Puchalski C. Training physicians as healers. AMA J Ethics. 2018;20(7):E655-E663.

42. Damiano RF, DiLalla LF, Lucchetti G, Dorsey JK. Empathy in medical students is moderated by openness to spirituality. Teach Learn Med. 2017;29(2):188-195. doi:10.1080/10401334.2016.1241714

43. Balboni MJ, Balboni TA. Hostility to Hospitality: Spirituality and Professional Socialization Within Medicine. Oxford: Oxford University Press; 2019.

44. Kruizinga R, Scherer-Rath M, Schilderman HJBAM, Puchalski CM, Laarhoven $\mathrm{H}$. Toward a fully fledged integration of spiritual care and medical care. J Pain Symptom Manage. 2018;55(3):1035-1040. doi:10. 1016/j.jpainsymman.2017.11.015

45. Abdel-Halim RE, Alkattan KM. Introducing medical humanities in the medical curriculum in Saudi Arabia: a pedagogical experiment. Urol Ann. 2012;4(2):73-79. doi:10.4103/0974-7796.95549

46. Ray C, Wyatt TR. Religion and spirituality as a cultural asset in medical students. J Relig Health. 2018;57(3):1062-1073. doi:10.1007/s10943017-0553-3

\section{Publish your work in this journal}

Advances in Medical Education and Practice is an international, peerreviewed, open access journal that aims to present and publish research on Medical Education covering medical, dental, nursing and allied health care professional education. The journal covers undergraduate education, postgraduate training and continuing medical education including emerging trends and innovative models linking education, research, and health care services. The manuscript management system is completely online and includes a very quick and fair peer-review system. Visit http://www.dovepress.com/testimonials.php to read real quotes from published authors. 